\title{
Comparison between Elderly Persons of the Urban Community, According to the Indicative of Depression
}

\author{
Lilane Maria Alves Silva, Sheron Hellen da Silva, Darlene Mara dos Santos Tavares, \\ Leiner Resende Rodrigues
}

The Federal University of Triângulo Mineiro, Uberaba, MG, Brazil

Email: lilanealves@yahoo.com.br, sheronhsilva@yahoo.com.br, darlenetavares@enfermagem.uftm.edu.br, leinerrr@bol.com.br

How to cite this paper: Silva, L.M.A., Silva, S.H., Tavares, D.M.S. and Rodrigues, L.R. (2017) Comparison between Elderly Persons of the Urban Community, According to the Indicative of Depression. Open Journal of Nursing, 7, 158-168. https://doi.org/10.4236/ojn.2017.72014

Received: December 21, 2016

Accepted: February 6, 2017

Published: February 9, 2017

Copyright $\odot 2017$ by authors and Scientific Research Publishing Inc. This work is licensed under the Creative Commons Attribution International License (CC BY 4.0).

http://creativecommons.org/licenses/by/4.0/

\begin{abstract}
Objectives: To compare the sociodemographic and economic profile, functional capacity, number of self-referred morbidities and level of physical activity among the elderly with and without indicative of depression. Methods: Cross-sectional and analytical study, with 980 elderly persons (250 with and 730 without indicative of depression) residing in the city of Uberaba, in the State of Minas Gerais, Brazil, between August 2012 and May 2013. We used the BOMFAQ Questionnaire, GDS 15, Katz Index, Lawton and Brody Scale and IPAQ. For data analysis, descriptive statistics and the Chi-square test ( $\mathrm{p}<$ 0.05 ) were used, in the program SPSS, version 17.0. Results: In the comparison between the groups, there were significant differences regarding the female gender $(p=0.009)$, education $(p=0.008)$, individual income $(p<0.001)$, activities of daily living $(\mathrm{p}<0.001)$, instrumental activities of daily living $(\mathrm{p}<$ $0.001)$ and number of morbidities $(\mathrm{p}<0.001)$. Conclusion: The comparison of the existence or not of depressive symptoms among the elderly enables a more effective planning of public policies aimed at health promotion and adequate treatment in cases of disease already present and the subsidization of preventive strategies, using data such as risk factors and associated factors and ways to research depression.
\end{abstract}

\section{Keywords}

Depression, Aged, Motor Activity, Activities of Daily Living

\section{Introduction}

The aging process can promote the emergence of chronic diseases, especially depression, which is a mental disorder of complex and multifactorial etiology 
[1].

Depression in the elderly is considered one of the most common health and important problems as a result of the significant prevalence. Among the elderly in the urban community, a study carried out in a municipality of the State of São Paulo, Brazil, has identified that $15.7 \%$ of them had depressive symptoms [1]. Another study carried out in the Cardiogeriatric Unit of the Clinics Hospital of the School of Medicine of São Paulo (InCor/HC-FMUSP), with 1020 elderly patients with heart disease, has found that approximately half of the study population suffered from major depression and $11 \%$ from minor depression [2]. We have to consider that estimates of depression in the elderly are quite varied because of the differences of the population studied and the diagnostic criteria adopted in population surveys.

The disease presents chronic evolution and has great potential for commitment of labor and social activities in general, especially when manifested in moderate or severe intensity. The most serious cases can lead to suicide [1]. Moreover, it has relationship with the socioeconomic and cultural conditions of elderly persons [3]. We can observe that some factors are associated with increased detection of depression: illiteracy, low educational level, female gender, low income; moreover, it has been found that the more severe the depression, the worse the self-perception of health. In addition, depression can be related to a lack of physical activity, cognitive deficits and functional incapacity for activities of daily living [4].

In this sense, the regular practice of physical activity has been described in the literature as a protective factor for the manifestation of depressive symptoms [1] [5].

In relation to functional capacity, it is known that the chronicity of depressive symptomatology has deleterious impacts on the functional status, which, in turn, can generate more depressive symptoms. The interaction of these factors can contribute to a progressive decline in the health status of the elderly population [6].

Biological changes from the depressive symptoms also increase the risks of developing Noncommunicable Diseases (NCD), leading to the exacerbation of the condition. Another factor to be highlighted is the limitation of daily life that the NCD can cause, increasing the chances of developing the psychiatric illness [7], which highlights once again the cyclical trend of interaction of the conditions presented by the elderly affected by the disease.

This panorama becomes even more critical when we consider the seriousness and proportions that NCD mean for the global Public Health [3] [8]. However, similarly to the limitation to the activities of daily living, the low level of physical activity is a modifiable risk factor for the reduction of the rates of depression among the elderly, and it can be addressed in Public Health programs [4].

Research conducted in a municipality in southern Brazil, with elderly persons in the community and institutionalized, showed that $81.46 \%$ of those who showed symptoms of depression reported not having hopes for the future and 
$69.9 \%$ of the elderly in the community reported "feeling lonely in the last month", against $21 \%$ of the institutionalized ones [9].

A study conducted with 351 elderly persons in Southeast Brazil has found a positive association between antidepressants and age and higher income range; however, the prevalence of depressive disorders in this municipality is greater in low-income population, thus showing the possibility of the existence of inequality in mental health care for this population [10].

Thus, it is necessary to increment studies that assess the health and living conditions of the elderly population, especially regarding depression, because of the repercussions on the life of the elderly. In addition, it is necessary the provision of conditions for the targeting of health actions, both in geriatric programs and in more general social policies.

In the literature, we can find a diversity of studies relating to depressive disorders in the elderly population, given its relevance to the health care of this age group [1] [3] [4]. This research has mainly contributed with the comparison between elderly persons in the community with and without indicative of depression.

This study has aimed to compare the sociodemographic and economic profile, functional capacity, level of physical activity and self-referred morbidities among the elderly with and without indicative of depression.

\section{Methods}

The research was characterized as observational, analytical, with cross design and as a household survey. The study is part of the master's thesis entitled Indicative of depression and associated factors in elderly persons of the urban community, of the Graduate Program StrictoSensu in Health Care of UFTM [11].

For the composition of the sample, a representative sample of the elderly population (obtained in previous research studies) residing in the urban area of Uberaba/MG of 2149 individuals was used. The sample calculation considered $95 \%$ confidence, $80 \%$ power, $4.0 \%$ margin of error for interval estimates and estimated proportion of $\mathrm{n}=0.5$ for the proportions of interest. The elderly persons were selected through proportional stratified sampling technique considering the various neighborhoods as strata.

The inclusion criteria were: to be 60 years old or over, do not present cognitive decline and residing in the urban area of the municipality of Uberaba/MG.

The following were excluded: the elderly who were hospitalized (14), who were not found after three consecutive attempts by the interviewer (183), who changed their addresses (193), who presented cognitive decline (160), who lived in the same residence (64) and other reasons (252). There were 303 losses, 266 due to death and 37 due to refusal to participate in the study.

Thus, 980 elderly persons met the criteria established, who were divided into two groups: the first one consisted of those with positive screening for depressive symptoms, called group with indicative of depression (composed of 250 individuals) and those with negative screening for depressive symptoms, called 
group without indicative of depression (composed of 730 individuals).

The interviews were carried out by nineteen interviewers properly oriented and trained regarding how to approach elderly persons in their home, the correct filling of the tool and the ethical issues related to the research. The period of data collection was from August 2012 to May 2013.

Six tools were used in total for data collection: the Mini-Mental State Examination (MMSE) that aims to assess the cognition of the elderly, translated and validated in Brazil, with the cutoff point considered according to the education level of the elderly [12].

The Brazilian Multidimensional Functional Assessment Questionnaire (BOMFAQ) was used for the collection of data relating to the identification, sociodemographic profile and self-referred morbidities. The original questionnaire was produced by Older Americans Resources and Services (OARS), prepared by Duke University (1978) and adapted in Brazil [13].

The instrument used for the tracking of depression in the elderly was the Geriatric Depression Scale (GDS), the Brazilian version of the GDS-15, specific to seniors. It is a dichotomous scale, in which participants were instructed to point the presence or absence of symptoms related to changes in mood and specific feelings such as helplessness, worthlessness, disinterest, boredom and happiness. The cutoff point $>5$ indicates positivity for the indicative of depression [14].

To assess the functional capacity of the elderly, we used the Katz Index. The instrument consists of questions that address the activities of daily living (ADLs) and allows the classification of the elderly into: independent for the six functions; dependent on one function; dependent on two functions; dependent on three functions; dependent on four functions; dependent on five functions; dependent on six functions [15].

The Lawton and Brody Scale was used to assess the instrumental activities of daily living. The instrument was adapted to the Brazilian context and had its reliability assessed, resulting in the classification of IADLs into: total dependence, partial dependence and independence [16].

To measure the level of physical activity, we used the International Physical Activity Questionnaire (IPAQ), long version for elderly persons, validated in Brazil [17]. The IPAQ covers four areas of physical activity: physical activity at work; as a means of transport; when carrying out household chores; and as recreation, sport, exercise and leisure. The instrument allows the classification of the elderly into insufficiently active, when the sum is less than 150 minutes per week, considering the four areas, and sufficiently active, in situations where the sum of minutes is equal to or greater than 150 per week in the aforementioned areas of physical activity [18].

The collected data were processed in microcomputer, by two persons, in double entry in the program Excel ${ }^{\circledast}$. Then, the consistency of the database was verified and corrected where needed. The database was transported to the software Statistical Package for the Social Sciences (SPSS), version 17.0, for analysis.

Exploratory (descriptive) analyses of the data were carried out, from the cal- 
culation of simple absolute and percentage frequencies. To perform the comparison between groups, the Chi-square test $(\mathrm{p}<0.005)$ was used.

Approval was obtained for the execution of the research from the Research Ethics Committee of the Federal University of Triângulo Mineiro, under Protocol No. 2265. Only after the consent of the interviewee and signature of said Term, the interview was started.

\section{Results}

Of the 980 elderly persons, $25.5 \%$ presented indicative of depression. Most of those with indicative of depression were females, 178 (71.2\%), while that number was limited to 72 individuals in males, accounting for $28.8 \%$ of the total. In the bivariate analysis, such percentage was significant, denoting that being female was a risk factor for the manifestation of depressive symptoms $(\mathrm{p}=0.009)$, Table 1.

The predominant age group, in both groups, was 70 - 80 years, with 123 $(49.2 \%)$ of them in the group with indicative of depression and $367(50.3 \%)$ in the group without indicative of depression. However, there was no association between the highest age group and the existence of indicative of depression $(\mathrm{p}=$ 0.510), Table 1.

Regarding marital status, widowhood was greatly reported by the portion of elderly persons with indicative of depression, 114 (45.6\%), and living with companion, by those without indicative of depression, 319 (43.7\%), Table 1.

Regarding education, there was a higher proportion of elderly persons with 1 5 years of study in both groups: 144 (57.6\%) of subjects with indicative of depression and $405(55.5 \%)$ without indication of depression. It was evidenced that lower education was linked to the presence of depressive symptoms, and this difference was significant when compared with elderly persons without indicative of depression ( $\mathrm{p}=0.008$ ), Table 1 .

Similarly in both groups, individual income of up to one minimum wage prevailed, namely, 152 (60.8\%) individuals among those with indicative of depression and 350 (47.9\%) among those without indicative of depression. The bivariate analysis was significant, demonstrating that the lower income was associated with the presence of depressive symptoms $(\mathrm{p}<0.001)$, Table 1 .

Regarding the ADLs, 23 (9.2\%) of the individuals presented dependence in the group with indicative of depression, and most of them, 16 individuals (6.4\%), reported the occurrence of dependence in the six functions. Similarly, in the group without indicative of depression, of the total of dependent elderly persons, $20(2.7 \%)$, most of them, 15 individuals (2.0\%), said to possess a functional incapacity. Elderly individuals with indicative of depression had higher functional incapacity to carry out the ADLs than those without indicative of depression, and this difference was significant $(\mathrm{p}<0.001)$, Table 2 .

Contrary to the higher occurrence of independence for the ADLs among the elderly, the measurement of functionality for the IADLs showed the prevalence 
Table 1. Frequency distribution of the sociodemographic and economic variables and their associations, according to the indicative of depression of elderly residents in the urban area of Uberaba/MG_-Brazil, 2013.

\begin{tabular}{|c|c|c|c|c|c|c|c|c|}
\hline \multirow{3}{*}{ Variables } & \multicolumn{8}{|c|}{ Indicative of depression } \\
\hline & \multicolumn{2}{|c|}{ Total } & \multicolumn{2}{|c|}{ Yes } & \multicolumn{2}{|c|}{ No } & \multirow[b]{2}{*}{${ }^{*} \mathrm{X}^{2}$} & \multirow[b]{2}{*}{$\mathrm{p}$} \\
\hline & $\mathrm{N}$ & $\%$ & $\mathrm{~N}$ & $\%$ & $\mathrm{~N}$ & $\%$ & & \\
\hline \multicolumn{9}{|c|}{ Gender } \\
\hline Female & 631 & 64.4 & 178 & 71.2 & 453 & 62.1 & 6.792 & 0.009 \\
\hline Male & 349 & 35.6 & 72 & 28.8 & 277 & 37.9 & & \\
\hline \multicolumn{9}{|c|}{ Age group } \\
\hline $60-70$ & 283 & 28.9 & 68 & 27.2 & 215 & 29.5 & & \\
\hline $70-80$ & 490 & 50.0 & 123 & 49.2 & 367 & 50.3 & 1.345 & 0.510 \\
\hline 80 or more & 207 & 21.1 & 59 & 23.6 & 148 & 20.3 & & \\
\hline \multicolumn{9}{|c|}{ Marital Status } \\
\hline Never married or lived with a partner & 48 & 4.7 & 15 & 6.0 & 33 & 4.5 & & \\
\hline Live with a spouse or partner & 418 & 42.7 & 99 & 39.6 & 319 & 43.7 & 3.572 & 0.312 \\
\hline Widow & 411 & 41.9 & 114 & 45.6 & 297 & 40.7 & & \\
\hline Separated/divorced & 103 & 10.5 & 22 & 8.8 & 81 & 11.1 & & \\
\hline \multicolumn{9}{|c|}{ Education } \\
\hline Illiterate & 212 & 21.6 & 66 & 26.4 & 146 & 20.0 & & \\
\hline $1-5$ years & 549 & 56.0 & 144 & 57.6 & 405 & 55.5 & 9.725 & 0.008 \\
\hline 5or more & 219 & 22.3 & 40 & 16.0 & 179 & 24.5 & & \\
\hline \multicolumn{9}{|c|}{ Individual Income } \\
\hline No income & 75 & 7.7 & 25 & 10.0 & 50 & 6.8 & & \\
\hline Uptolminimumwage & 502 & 51.2 & 152 & 60.8 & 350 & 47.9 & 20.04 & $<0.001$ \\
\hline$>1$ minimum wage & 403 & 41.1 & 73 & 29.2 & 330 & 45.2 & & \\
\hline
\end{tabular}

*Pearson's chi-square association coefficient.

Table 2. Frequency distribution of the variables of functional capacity and their associations with the indicative of depression in elderly residents in the urban area of Uberaba/MG-Brazil, 2013.

\begin{tabular}{|c|c|c|c|c|c|c|c|c|}
\hline \multirow{3}{*}{ Variables } & \multicolumn{4}{|c|}{$\mathrm{E}=$ Indicative of depression } & & & \multirow[b]{3}{*}{${ }^{*} \mathrm{X}^{2}$} & \multirow[b]{3}{*}{$\mathrm{p}$} \\
\hline & \multicolumn{2}{|c|}{ Total } & \multicolumn{2}{|c|}{ Yes } & \multicolumn{2}{|c|}{ No } & & \\
\hline & $\mathrm{N}$ & $\%$ & $\mathrm{~N}$ & $\%$ & $\mathrm{~N}$ & $\%$ & & \\
\hline \multicolumn{9}{|c|}{$\mathrm{ADLs}^{\mathrm{a}}$} \\
\hline Dependent & 43 & 4.4 & 23 & 9.2 & 20 & 2.7 & 18.52 & $<0.001$ \\
\hline Independent & 937 & 95.6 & 227 & 90.8 & 710 & 97.3 & & \\
\hline \multicolumn{9}{|c|}{ 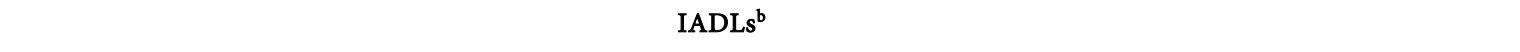 } \\
\hline Dependent & 689 & 70.3 & 202 & 80.8 & 487 & 66.7 & 18.05 & $<0.001$ \\
\hline Independent & 291 & 29.7 & 48 & 19.2 & 243 & 33.3 & & \\
\hline
\end{tabular}

a. Activities of Daily Living, b. Instrumental Activities of Daily Living. ${ }^{*}$ Pearson’s chi-square association coefficient. 
of dependence, corresponding to $202(80.8 \%)$ of the individuals in the group with indicative of depression and 487 (66.7\%) among those without indicative of depression. The findings indicated that there was association between functional incapacity to carry out IADLs and the presence of depressive symptoms ( $\mathrm{p}<$ $0.001)$, Table 2.

In relation to the level of physical activity, in both groups there was a predominance of sufficiently active individuals. However, among those with depressive symptoms, 94 (37.6\%) were insufficiently active, and in those without indicative of depression such percentage was lower, 224 individuals (30.7\%) The bivariate analysis was significant, demonstrating that lower levels of physical activity were associated with the presence of the indicative of depression $(p=0.044)$, Table 3.

We highlight that, among the four domains assessed by the IPAQ (physical activity at work; as a means of transport; when carrying out household chores; and as recreation, sport, exercise and leisure), those that contributed most to the insufficiency between the elderly with and without indicative of depression were physical activity at work and physical activity as recreation, sport, exercise and leisure. On the other hand, the domain with the most minutes spent was related to household chores.

Regarding the total number of morbidities, we obtained, in both groups, the prevalence of five or more problems, corresponding to $76.4 \%$ among those with indicative of depression and 53.6\% among those without indicative of depression. The difference was significant $(\mathrm{p}<0.001)$, so that multiple morbidities were associated with the indicative of depression.

\section{Discussion}

The higher incidence of depression among female individuals corroborates with studies in Brazil and in the world [1] [5]. This fact may be associated with higher life expectancy of women compared to the male population, demonstrating the feminization of aging [19] [20]. Additionally, several hypotheses justify the predominance of the female gender, such as the hormonal changes in menopause, as well as beginning of early medical follow-up, health life habits and greater adherence to activities that prevent diseases [21].

Table 3. Frequency distribution of the variables of level of physical activity and their associations, according to the indicative of depression of elderly residents in the urban area of Uberaba/MG-Brazil, 2013.

\begin{tabular}{|c|c|c|c|c|c|c|c|c|}
\hline \multirow{3}{*}{ Varibles } & \multicolumn{4}{|c|}{$\mathrm{E}=$ Indicative of depression } & & & & \\
\hline & \multicolumn{2}{|c|}{ Total } & \multicolumn{2}{|c|}{ Yes } & \multicolumn{2}{|c|}{ No } & \multirow[b]{2}{*}{${ }^{\star} \mathrm{X}^{2}$} & \multirow[b]{2}{*}{$\mathrm{p}$} \\
\hline & $\mathrm{N}$ & $\%$ & $\mathrm{~N}$ & $\%$ & $\mathrm{~N}$ & $\%$ & & \\
\hline \multicolumn{9}{|c|}{ Level of Physical Activity } \\
\hline Insufficiently active & 318 & 32.4 & 94 & 37.6 & 224 & 30.7 & 4.063 & 0.044 \\
\hline Sufficiently active & 662 & 67.6 & 156 & 62.4 & 506 & 69.3 & & \\
\hline
\end{tabular}

*Pearson's chi-square association coefficient. 
The lack of association between age group and the indicative of depression in this investigation is similar to the systematic review that has identified inconsistent results regarding this relationship [5]. However, it is assumed that the addition of depressive symptoms at the end of life is strongly associated with loneliness, dependence and lack of social network support [10]. The estimates indicate that more than $50 \%$ of the depressive disorders in the elderly represent a new condition resulting from old age [6].

Although there has been no association between marital status and indicative of depression, it is important to consider that the loss of the spouse is related to the manifestation of depressive symptoms, leading to feelings of sadness and loneliness [22].

Regarding education, it should be noted that the number of years of study are considered as protective factor against depression in the elderly, as the greater educational level allows more resources to be used to cope with stressing factors in life and greater access to health services [2] [23] [24].

Regarding functional capacity, there was greater functional incapacity for IADLs among the elderly with indicative of depression than among those without indicative of depression, thus corroborating with the findings of a systematic review which suggests that depression in the elderly may be more associated with functional decline than with biological factors, such as age and gender [5]. Therefore, it is important for the health team to act on aspects related to the functional limitations of elderly persons aiming at preventing functional disability and promoting good functionality.

Regarding the comparison of the level of physical activity according to indicative of depression, a population-based study with 1563 elderly persons in São Paulo/Brazil has identified association between lower prevalence of depression diagnosis and practice of physical exercise [1]. In this study, the domain of physical activity that had the lowest score, in both groups, was in relation to recreation, sports, exercise and leisure $(\mathrm{Md}=0 \mathrm{~min})$. Possible explanations for this low demand may be related with the predominance of low-income individuals both in the group with indicative of depression and in the group without indicative of depression. Research studies show that less time spent in the domain of physical activity is observed in persons with less economic power, because of little investment in physical activity facilities in the poorest neighborhoods by the public authorities [25].

The highest median found was in the domain of physical activity of household chores, and among those with indicative of depression this value corresponded to 120 minutes and among those without indicative of depression it was limited to 90 minutes. This can be explained by the fact that, in both groups, females were predominant. In this sense, by occupying themselves longer with household chores, it is possible that women refrain from the practice of physical activity of recreational nature.

The study has found that the prevalence of depressive symptoms increases as there is an increase in the number of morbidities. Namely, the values were: $19 \%$ 
of depressive symptoms in the elderly with no morbidity, $34 \%$ in those who had one morbid, $44 \%$ among those who had two morbidities and 53\% when the number of morbidities was equal to or greater than three $(\mathrm{p}<0.001)$ [26]. It is suggested that the prognosis of depressive diagnosis is worsened by the presence of comorbidities, and we should also consider the greater fragility of the defenses that comes from aging. In this way, the association of diseases and functional limitations can impact the mental health of the elderly and hinder the recognition of depression [27], thus requiring greater attention from the health team.

\section{Conclusions}

The proportion of elderly persons with indicative of depression amounted to $25.5 \%$. In both groups, the highest percentages were concentrated on the female individuals, aged $70 \wedge 80$ years, with $1 \wedge 5$ years of education and income of up to one minimum salary. Regarding marital status, widowers were predominant among those with indicative of depression. On the other hand, among those without indicative of depression, the percentage of elderly persons who lived with spouse or partner was higher. Living together was the housing arrangement that was the most reported by the elderly of the two groups. In relation to functional capacity, there was a prevalence of independence to carry out ADLs and dependence for IADLs, in both groups. Similarly, the proportion of sufficiently active individuals was higher, in relation to the level of physical activity. The most recurring number of morbidities was five or more problems, referred by the individuals of both groups.

We highlight that the research is limited to obtaining the data on morbidities through self-report, which may result in misdiagnosis. In addition, the crosssectional design, adopted in this research, slips in the appointment of causal inferences, not allowing us to explore the relations of causality between the variables studied.

Nevertheless, we can conclude that there is a need to focus on the development of public policies and the implementation of health promotion strategies aimed at the elderly population, intervening in the risk factors for the manifestation of depressive symptoms, whose impact on the health of this population seems to be expressive.

\section{Acknowledgements}

\section{FAPEMIG, CNPq.}

\section{References}

[1] Barcelos-Ferreira, R., et al. (2012) Clinical and Sociodemographic Factors in a Sample of Older Subjects Experiencing Depressive Symptoms. International Journal of Geriatric Psychiatry, 27, 924-930. https://doi.org/10.1002/gps.2803

[2] Rodrigues, G.H.P., et al. (2015) Depressão como Determinante Clínico de Dependência e Baixa Qualidade de Vida em Idosos Cardiopatas. Arquivos Brasileiros de Cardiologia, 104, 443-449.

[3] Oliveira, M.G., et al. (2012) Sintomatologia de depressão autorreferida por idosos 
que vivem em comunidade. Ciência e Saúde Coletiva, 17, 2191-2198. https://doi.org/10.1590/S1413-81232012000800029

[4] Nogueira, E.L., et al. (2014) Rastreamento de sintomas depressivos em idosos na Estratégia Saúde da Família. Revista de Saúde Pública, 48, 368-377.

https://doi.org/10.1590/S0034-8910.2014048004660

[5] Büchtemann, D., et al. (2012) Incidence of Late-Life Depression: A Systematic Review. Journal of Affective Disorders, 142, 172-179. https://doi.org/10.1016/j.jad.2012.05.010

[6] Milaneschi, Y. and Penninx, B.W.J.H. (2014) Depression in Older Persons with Mobility Limitations. Current Pharmaceutical Design, 20, 3114-3118. https://doi.org/10.2174/13816128113196660060

[7] Katon, W.J. (2011) Epidemiology and Treatment of Depression in Patients with Chronic Medical Illness. Dialogues in Clinical Neuroscience, 13, 7-23.

[8] Santos, V.C.F., Kalsing, A., Ruiz, E.N.F., Roese, A. and Gerhardt, T.E. (2013) Perfil das internações por doenças crônicas não-transmissíveis sensíveis à atenção primária em idosos da Metade Sul do RS. Revista Gaúcha de Enfermagem, 34, 124-131. https://doi.org/10.1590/S1983-14472013000300016

[9] Teston, E.F., Carreira, L. and Marcon, S.S. (2014) Sintomas depressivos em idosos: comparação entre residentes em condomínio específico para idoso e na comunidade. Revista Brasileira de Enfermagem, 67, 450-456.

[10] Loyola Filho, A.I., et al. (2014) Tendências no uso de antidepressivos entre idosos mais velhos: Projeto Bambuí. Revista Saúde Pública, 48, 857-865. https://doi.org/10.1590/S0034-8910.2014048005406

[11] Silva, L.M.A. (2013) Indicativo de depressão e fatores associados em idosos da comunidade urbana. Dissertation, Universidade Federal do Triângulo Mineiro, Uberaba.

[12] Bertolucci, P.H.F., Brucki, S.M.D., Campacci, S. and Juliano, Y. (1994) Mini Exame do Estado Mental e Escolaridade. Arquivos de Neuropsiquiatria, 52, 1-7. https://doi.org/10.1590/S0004-282X1994000100001

[13] Ramos, L.R. (1987) Growing Old in São Paulo, Brazil: Assessment of Health Status and Family Support of the Elderly of Different Socio-Economic Strata Living in the Community. Doctor Theses, London School Hygiene and Tropical of Medicine, London.

[14] Almeida, O.P. and Almeida, S.A. (1999) Confiabilidade da versão brasileira da Escala de Depressão em Geriatria (GDS) versão reduzida. Arquivos de Neuropsiquiatria, 57, 421-426. https://doi.org/10.1590/S0004-282X1999000300013

[15] Lino, V.T.S., Pereira, S.E.M., Camacho, L.A.B., Ribeiro Filho, S.T. and Buksman, S. (2008) Adaptação transcultural da Escala de Independência em Atividades da Vida Diária (Escala de Katz). Cadernos de Saúde Pública, 24, 103-112. https://doi.org/10.1590/S0102-311X2008000100010

[16] Santos, R.L. and Virtuoso Júnior, J.S. (2008) Confiabilidade da versão brasileira da escala de atividades instrumentais da vida diária. Revista Brasileira de Promoção de Saúde, 21, 290-296. https://doi.org/10.5020/18061230.2008.p290

[17] Benedetti, T.R.B., Antunes, P.D.C., Rodriguez-Añez, C.R., Mazo, G.Z. and Petroski, É.L (2007) Reprodutibilidade e validade do Questionário Internacional de Atividade Física (IPAQ) em homens idosos. Revista Brasileira de Medicina do Esporte, 13, 11-16. https://doi.org/10.1590/S1517-86922007000100004

[18] Pate, R.R., Pratt, M., Blair, S.N., Haskell, W.L., Macera, C.A., Bouchard, C., et al. (1995) Physical Activity and Public Health: A Recommendation from the Centers 
for Disease Control and Prevention and the American College of Sports Medicine. JAMA, 273, 402-407. https://doi.org/10.1001/jama.1995.03520290054029

[19] Paula, A.F.M., Ribeiro, L., D’Elboux, M. and Guariento, M. (2013) Avaliação da capacidade funcional, cognição e sintomatologia depressiva em idosos atendidos em ambulatório de Geriatria. Revista da Sociedade Brasileira de Clínica Médica, 11, 212-218. http://files.bvs.br/upload/S/1679-1010/2013/v11n3/a3767.pdf

[20] Silva, E.F., Vieira, V., Laste, P. and Torres, I. (2013) Prevalência de morbidades e sintomas em idosos: Um estudo comparativo entre zonas rural e urbana. Ciência e saúde coletiva, 18, 1029-1040. https://doi.org/10.1590/S1413-81232013000400016

[21] Castro e Silva, I.M. and Andrade, K.L. (2013) Avaliação da qualidade de vida de idosos atendidos em um ambulatório de Geriatria da região Nordeste do Brasil. $R e$ vista Brasileira de Clínica Médica, 11, 129-134.

[22] Cohen, R., Paskulin, L.M.G. and Prieb, R.G.G. (2015) Prevalência de sintomas depressivos entre idosos em um serviço de emergência. Revista Brasileira de Geriatria e Gerontologia, 18, 307-317. https://doi.org/10.1590/1809-9823.2015.14052

[23] Minghelli, B., Tomé, B., Nunes, C., Neves, A. and Simões, C. (2013) Comparação dos níveis de ansiedade e depressão entre idosos ativos e sedentários. Revista de Psiquiatria Clínica, 40, 71-76. https://doi.org/10.1590/S0101-60832013000200004

[24] Borges, L.J., Benedetti, T., Xavier, A. and d'Orsi, E. (2013) Fatores associados aos sintomas depressivos em idosos: Estudo EpiFloripa. Revista Saúde Pública, 47, 701710. https://doi.org/10.1590/S0034-8910.2013047003844

[25] Valadares, A.L., Carvalho, E.D., Costa-Paiva, L.H., Morais, S.S. and Pinto-Neto, A.M. (2011) Association between Different Types of Physical Activities and Quality of Life in Women Aged 60 Years or over. Revista da Associação Médica Brasileira, 57, 450-455. https://doi.org/10.1590/S0104-42302011000400021

[26] Manjubhashini, S., Krishnababu, G. and Krishnaveni, A. (2013) Epidemiological Study of Depression among Population above 60 Years in Visakhapatnam, India. International Journal of Medical Science and Public Health, 2, 695-702. https://doi.org/10.5455/ijmsph.2013.030520133

[27] Cavalcante, F.G., Minayo, M.C. and Mangas, R.M.N. (2013) Diferentes faces da depressão no suicídio em idosos. Ciência e Saúde Coletiva, 18, 2985-2994. https://doi.org/10.1590/S1413-81232013001000023 
Submit or recommend next manuscript to SCIRP and we will provide best service for you:

Accepting pre-submission inquiries through Email, Facebook, LinkedIn, Twitter, etc. A wide selection of journals (inclusive of 9 subjects, more than 200 journals)

Providing 24-hour high-quality service

User-friendly online submission system

Fair and swift peer-review system

Efficient typesetting and proofreading procedure

Display of the result of downloads and visits, as well as the number of cited articles Maximum dissemination of your research work

Submit your manuscript at: http://papersubmission.scirp.org/

Or contact ojn@scirp.org 